\title{
Endoscopic extraction of a special foreign body impacted in the colon
}

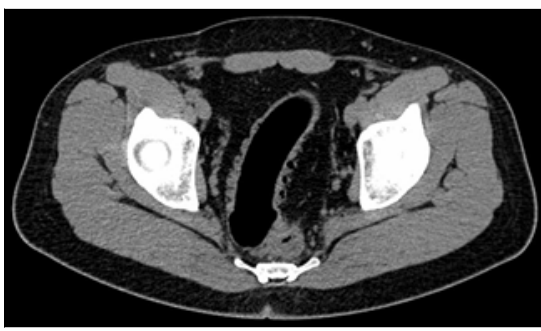

- Fig. 1 Abdominal computed tomography image showing the long foreign body.

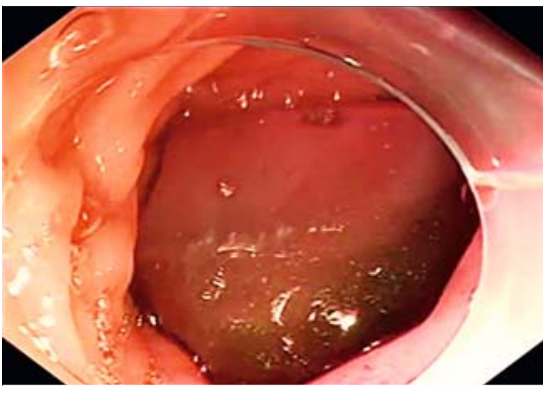

Fig. 2 Endoscopic view of the foreign body.

A 22-year-old man was admitted to the emergency department reporting insertion of a long foreign body into his anus 6 hours previously. Physical examination showed no signs of peritonitis. An abdominal computed tomography (CT) scan showed the foreign body in the descending colon and proximal rectum, with no signs of perforation ( $\triangleright$ Fig. 1). Emergent endoscopy was performed and showed that the foreign body was $35 \mathrm{~cm}$ from the anus and completely obstructing the bowel lumen ( $\triangleright$ Fig. 2).

We used a polypectomy snare and grasping forceps in succession to attempt to remove the foreign body but failed, despite several attempts, owing to the limited space between the foreign body and the bowel wall, and the slippery surface of the foreign body. Subsequently, we inserted two balloons (one at the proximal end of the foreign body and the other at the distal end) under fluoroscopic guidance

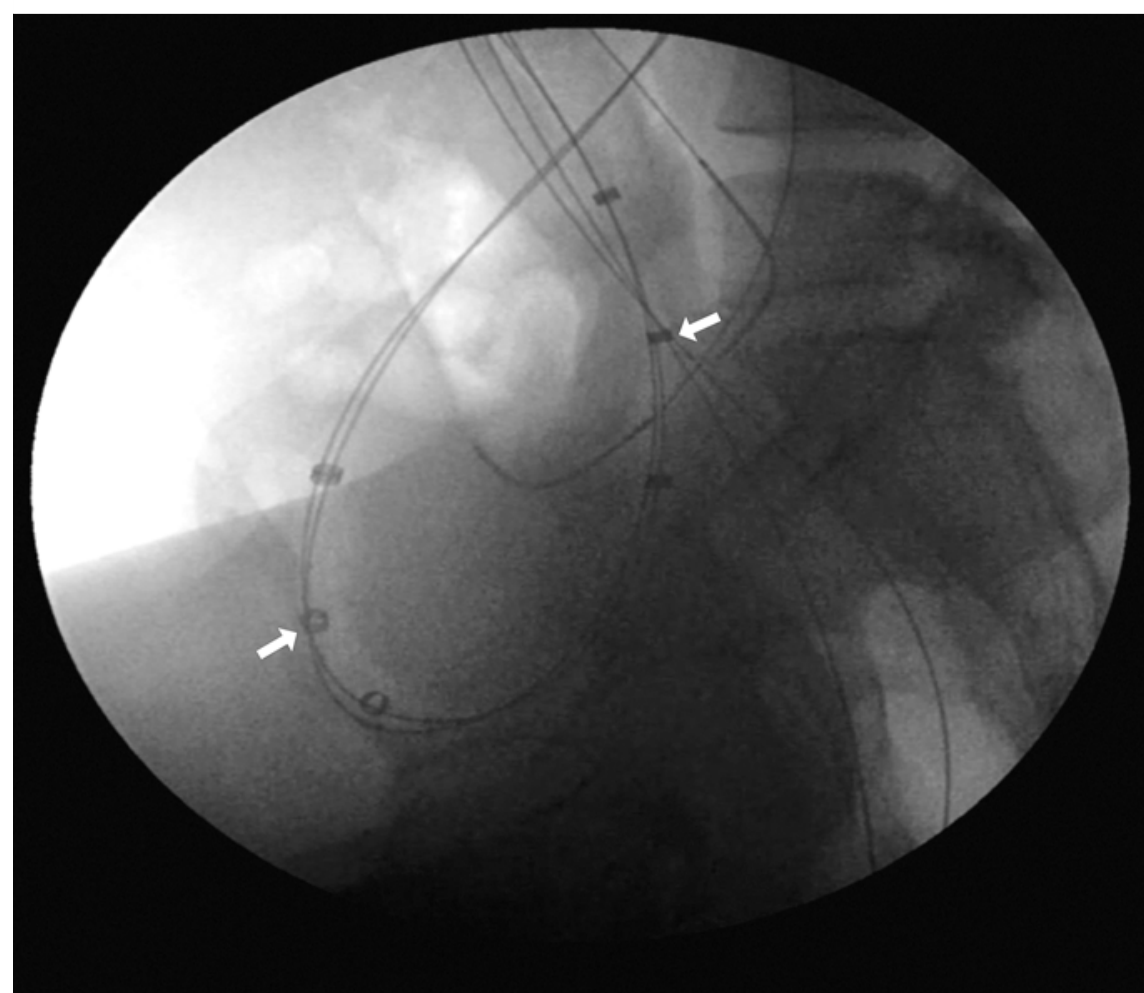

Fig. 3 Fluoroscopic image showing the two inserted balloons (arrows) at either end of the foreign body.

( $\triangleright$ Fig.3), and were able to pull the foreign body out by about $5 \mathrm{~cm}$. Although further movement could not be achieved using this method, it did create more space between the foreign body and the bowel lumen. We then returned to the combination of the snare and grasping forceps to extract the foreign body ( Fig.4). Finally, the foreign body was grasped by the snare and then extracted easily ( $\triangleright$ Video 1 ). The foreign body was about $46 \mathrm{~cm}$ in length and $3.5 \mathrm{~cm}$ in diameter (>Fig.5). The patient was discharged on the same day, with no further discomfort.

Snares are commonly used to extract long foreign bodies [1]; however, in some cases, the procedure can be difficult because of the location, size, shape, or other features of the foreign body, meaning grasping forceps or balloons

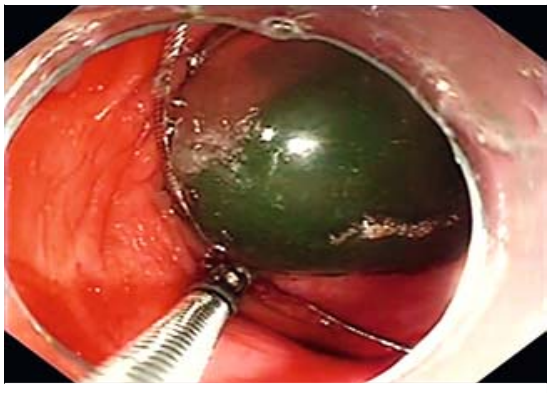

- Fig. 4 Endoscopic view showing the combined use of the snare and grasping forceps to extract the foreign body.

may play an unexpected role [2,3]. As presented in this case, a combination of two or more devices may achieve better results if a single approach does not work.

Endoscopy_UCTN_Code_TTT_1AQ_2AH 


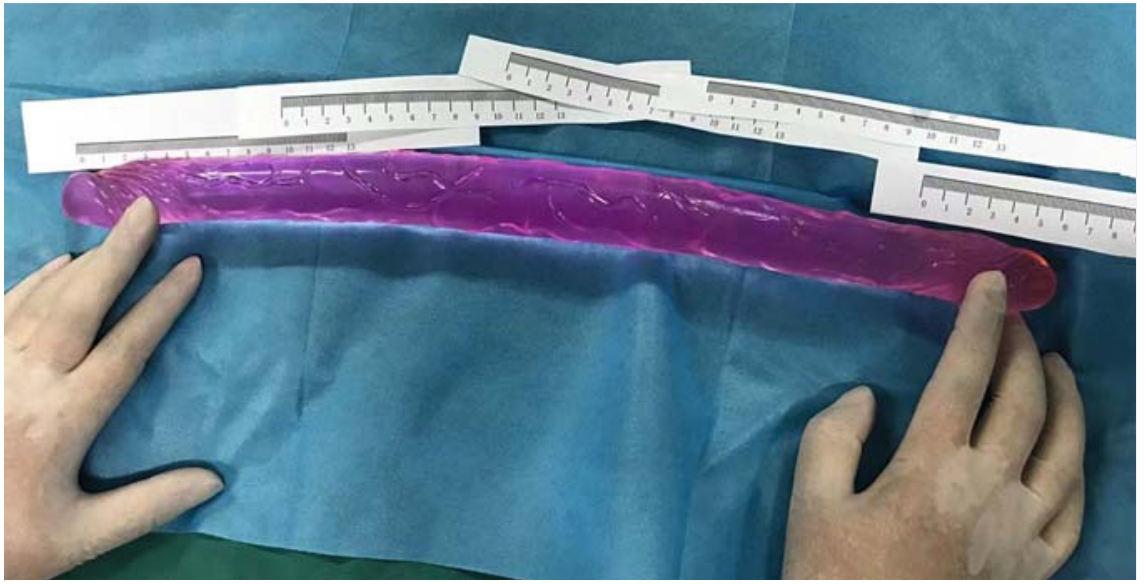

Fig. 5 Photograph of the extracted foreign body, which was $46 \mathrm{~cm}$ in length.

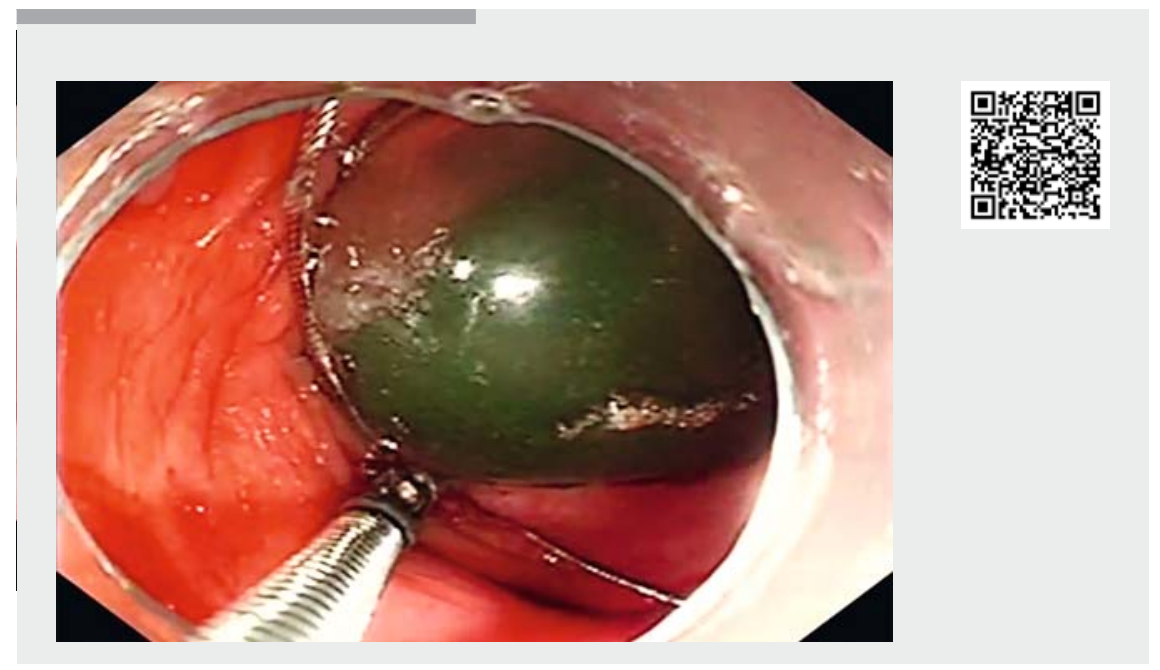

$\checkmark$ Video 1 Endoscopic extraction of a special foreign body that was impacted in the colon.
[2] Ye L, Zeng X, Wang $X$ et al. Endoscopic removal of two long iron rods impacted in the stomach. Endoscopy 2019; 51: E71-E72

[3] Billi P, Bassi M, Ferrara F et al. Endoscopic removal of a large rectal foreign body using a large balloon dilator: report of a case and description of the technique. Endoscopy 2010; 42 (Suppl. 02): E238

\section{Bibliography}

DOI https://doi.org/10.1055/a-1097-5302

Published online: 17.2.2020

Endoscopy 2020; 52: E287-E288

(c) Georg Thieme Verlag KG

Stuttgart · New York

ISSN 0013-726X

\section{ENDOSCOPY E-VIDEOS \\ https://eref.thieme.de/e-videos}

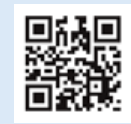

Endoscopy E-Videos is a free access online section, reporting on interesting cases and new techniques in gastroenterological endoscopy. All papers include a high quality video and all contributions are freely accessible online.

This section has its own submission website at https://mc.manuscriptcentral.com/e-videos

\section{Acknowledgments}

We acknowledge the support from the Health Commission of Sichuan Province (GB2018001).

\section{Competing interests}

The authors declare that they have no conflict of interest.

The authors

Yilong Feng*, Nianhong Wu*, Liansong Ye, Xianglei Yuan, Bing Hu

Department of Gastroenterology, West China Hospital, Sichuan University, Chengdu, Sichuan, China

\footnotetext{
* These authors contributed equally to this work.
}

Corresponding author

\section{Bing Hu, MD}

No. 37 Guo Xue Alley, Wu Hou District, Chengdu City, 610041, Sichuan Province, China hubingnj@163.com

\section{References}

[1] Birk M, Bauerfeind P, Deprez PH et al. Removal of foreign bodies in the upper gastrointestinal tract in adults: European Society of Gastrointestinal Endoscopy (ESGE) Clinical Guideline. Endoscopy 2016; 48: 489-496 